\title{
Determination of Sub-ppm Levels of Silver in Heat-Resisting Alloys by Graphite Furnace Atomic Absorption Spectrometry*
}

\author{
By Osamu Kujirai**, Takeshi Kobayashi** and Emiko Sudo**
}

\begin{abstract}
A rapid and simple analytical method has been developed for the determination of sub-ppm levels of Ag in Ni- and Co-base heat-resisting alloys by graphite furnace atomic absorption spectrometry. Nickel or Co, a base element of heat-resisting alloys, did not affect the absorbance of Ag. The effects of the other elements and acids on the absorbance of Ag were also studied. As a result, the acid solutions of $\mathrm{Ag}$ were used as the calibration solutions for the determination of sub-ppm levels of $\mathrm{Ag}$ in complex heat-resisting alloys. The results obtained by the calibration curve method agreed well with those by the standard addition method. The detection limit of $\mathrm{Ag}$ was $0.005 \mathrm{ppm}$ in the sample by the method described. This method, however, can not be applied for the determination of $\mathrm{Ag}$ in Co-base heat-resisting alloys containing large quantities of $\mathrm{Al}$ and $\mathrm{Ti}$ because of the interferences.
\end{abstract}

(Received October 31, 1977)

\section{Introduction}

It has been known that the impurities having a low melting point have harmful effects on the mechanical properties of heat-resisting alloys even if present at very low concentrations. Silver is one of them. Burke ${ }^{(1)}$ studied solvent extraction-flame atomic absorption spectrometry for the determination of trace quantities of $\mathrm{Ag}$ in Ni-base alloys. Kirk et al. ${ }^{(2)}$ determined trace quantities of $\mathrm{Ag}$ in high-Ni alloys by ion exchange-flame atomic absorption spectrometry. These methods are sensitive but their procedures are complicated and time-consuming. Moreover, the nebulization and combustion of organic solvents in flame atomic absorption spectrometry may be harmful to the health and the environmental preservation. Graphite furnace atomic absorption spectrometry has advantages of the high sensitivity and the simplified procedure over flame atomic absorption spectrometry and allows chemical separation to be avoided. Dulski and Bixler ${ }^{(3)}$ determined trace impurities in Ni-base heatresisting alloys by graphite furnace atomic

* This paper was presented at the Meeting of the Japan Institute of Metals, held at Hiroshima on October, 1977.

** Division of Metallurgical Chemistry, National Research Institute for Metals, Nakameguro, Meguro-ku, Tokyo 153, Japan.

Trans. JIM absorption spectrometry, but they did not determine Ag. They used a single-point method of standard addition rather than a calibration curve method to avoid the matrix effects. Recently, the present authors ${ }^{(4)}$ have studied the direct determination of trace quantities of $\mathrm{Pb}$ and $\mathrm{Bi}$ after the acid dissolution of $\mathrm{Ni}$ - and Co-base heat-resisting alloys by graphite furnace atomic absorption spectrometry.

This paper describes the application of graphite furnace atomic absorption spectrometry for the determination of sub-ppm levels of $\mathrm{Ag}$ in $\mathrm{Ni}$ - and Co-base heat-resisting alloys.

\section{Experimental}

\section{Equipment}

A Perkin-Elmer Model 403 atomic absorption spectrophotometer, equipped with a Model HGA-2100 graphite furnace and a deuterium arc background corrector, was used. A Hamamatsu TV hollow cathode lamp was used as the Ag light source. Absorbance was recorded with a Hitachi Model 056 recorder. Argon was used as the purge gas. A thermocouple or an optical pyrometer was used for the furnace temperature measurements.

\section{Reagents and solutions}

Nitric acid and hydrofluoric acid used were of analytical reagent grade. Stock standard

1978 Vol. 19 
Table 1 Chemical composition of heat-resisting alloys used. (wt \%)

\begin{tabular}{lllllllllllr}
\hline \hline Alloy & $\mathrm{Ni}$ & $\mathrm{Cr}$ & $\mathrm{Co}$ & $\mathrm{Al}$ & $\mathrm{Ti}$ & $\mathrm{Mn}$ & $\mathrm{Fe}$ & $\mathrm{Nb}$ & $\mathrm{Mo}$ & $\mathrm{Ta}$ & $\mathrm{W}$ \\
\hline NBS 349 (Waspaloy) & 57.2 & 19.5 & 14.0 & 1.2 & 3.1 & & & & 4.0 & & \\
Inconel 738 LC & 61.6 & 15.8 & 8.3 & 3.4 & 3.4 & & & & 1.8 & 1.7 & 2.6 \\
MAR-M 246 & 57.7 & 10.1 & 9.9 & 5.5 & 1.5 & & & & 2.6 & 1.5 & 10.9 \\
Udimet C0263 & 50.9 & 20.1 & 19.9 & & 2.2 & & & & 5.8 & & \\
\hline NBS 168 (S-816) & 20.3 & 20.3 & 41.2 & & & 1.5 & 3.4 & 3.0 & 4.0 & 1.0 & 4.0 \\
WI-52 & & 21.2 & 62.5 & & & & 2.0 & 1.8 & & & 10.4 \\
Modified S-816 & 20.0 & 20.2 & 45.6 & & & & & 4.0 & 4.1 & & 3.7 \\
\hline \hline
\end{tabular}

solution containing $1000 \mu \mathrm{g} / \mathrm{m} \ell$ of $\mathrm{Ag}$ was prepared by dissolving high-purity metal of Ag (Johnson Matthey Chemicals Ltd.) in dilute nitric acid and was stored in the dark. Working standard Ag solutions of lower concentrations were prepared daily to avoid the loss of Ag due to adsorption ${ }^{(5)}$ by diluting the stock standard solution with dilute nitric acid. The other standard solutions were also prepared by the dissolution of high-purity metals $\mathrm{Al}, \mathrm{Ti}, \mathrm{Cr}$, $\mathrm{Mn}, \mathrm{Fe}, \mathrm{Co}, \mathrm{Ni}, \mathrm{Zr}, \mathrm{Nb}, \mathrm{Mo}, \mathrm{Ta}$, and $\mathrm{W}$. The concentrations of $\mathrm{Ag}$ added to the sample solutions or matrix solutions were $0.005 \sim$ $0.01 \mu \mathrm{g} / \mathrm{m} \ell$. Solutions containing total metal concentrations of $10 \sim 20 \mathrm{mg} / \mathrm{m} \ell$ were used to select optimum analytical conditions.

\section{Heat-resisting alloys used}

Table 1 shows the chemical composition of the heat-resisting alloys used. NBS 349 (Waspaloy), Inconel 738 LC, MAR-M 246, and Udimet $\mathrm{CO} 263$ are Ni-base heat-resisting alloys. NBS 168 (S-816), WI-52, and modified S-816 are Co-base heat-resisting alloys. Standard alloys containing known amounts of $\mathrm{Ag}$ were not available. However, standard alloys such as NBS "benchmark" standards seem at present to be one of the most suitable samples for a comparison of the analytical results.

\section{Proposed procedure}

Dissolve $0.5 \mathrm{~g}$ of a heat-resisting alloy in $12 \mathrm{~m} \ell$ of a $1: 1: 1$ mixture of nitric acid, hydrofluoric acid and water by warming in a Pt beaker. After the complete dissolution of the alloy, cool and transfer the solution into a $50-\mathrm{m} \ell$ polyethylene volumetric flask. Dilute the solution to the mark with distilled water. Prepare calibration solutions by diluting the
Table 2 Operating parameters.

\begin{tabular}{lc}
\hline Analyte & $\mathrm{Ag}$ \\
\hline Wavelength $(\mathrm{nm})$ & 328.07 \\
Spectral band width $(\mathrm{nm})$ & 0.7 \\
Lamp current $(\mathrm{mA})$ & 12 \\
Ar flow rate $(\mathrm{m} \ell / \mathrm{min})$ & $\mathrm{ca} .60$ \\
Drying temperature $\left({ }^{\circ} \mathrm{C}\right)$ & 80 \\
Drying time $(\mathrm{s})$ & 30 \\
Ashing temperature $\left({ }^{\circ} \mathrm{C}\right)$ & 500 \\
Ashing time $(\mathrm{s})$ & 60 \\
Atomizing temperature $\left({ }^{\circ} \mathrm{C}\right)$ & 2400 \\
Atomizing time $(\mathrm{s})$ & 7 \\
Solution volume $(\mu \ell)$ & 20 \\
\hline \hline
\end{tabular}

stock standard $\mathrm{Ag}$ solution and adjusting the kind and concentration of acids. Pipette $20 \mu l$ of the solutions into the graphite furnace by an Eppendorf micropipette with plastic disposable tip. Operate the set program of the HGA controller under the conditions shown in Table 2. Interrupt the flow of the purge gas during the atomization for the increase in sensitivity. After the atomization, operate the high temperature (nominal temperature $2500^{\circ} \mathrm{C}$ ) treatment of the furnace for several seconds under the flow of the purge gas to remove the residual metals in the graphite furnace. Prepare a calibration curve and calculate the concentration of Ag.

\section{Results and Discussion}

\section{Optimum analytical conditions}

The drying temperature and time had little effect on the absorbance of $\mathrm{Ag}$ and were set to be $80^{\circ} \mathrm{C}$ and $30 \mathrm{~s}$, respectively. The ashing temperature curves were investigated for $\mathrm{Ag}$ in the acid solution and in the solutions contain- 
ing the Ni matrix, the Co matrix, and $\mathrm{Ni}$ - and Co-base heat-resisting alloys. NBS 349 or Inconel 738 LC, and NBS 168 were, respectively, used for representatives of $\mathrm{Ni}$ - and $\mathrm{Co}-$ base heat-resisting alloys. The optimum ashing temperature was selected to be $500^{\circ} \mathrm{C}$, which was a little below the temperatures where the loss of Ag began. The ashing time had no effect on the absorbance of $\mathrm{Ag}$ between $60 \mathrm{~s}$ and $180 \mathrm{~s}$, and was therefore decided to be $60 \mathrm{~s}$. The atomizing temperature curves for $\mathrm{Ag}$ were also investigated in the same solutions used for the study of the optimum ashing temperature. The optimum atomizing temperature was selected to be $2400^{\circ} \mathrm{C}$, which provided a maximum sensitivity for $\mathrm{Ag}$ in all the solutions used. The atomizing time of $7 \mathrm{~s}$ was sufficient for the determination of $\mathrm{Ag}$.

It is the most useful to use nitric acid and hydrofluoric acid for the dissolution of a wide variety of complex $\mathrm{Ni}$ - and Co-base heatresisting alloys. The effects of the amounts of acids on the absorbance of $\mathrm{Ag}$ in the acid solution and in the solutions containing the $\mathrm{Ni}$ matrix, the $\mathrm{Co}$ matrix, and $\mathrm{Ni}$ - and Co-base heat-resisting alloys were investigated. As a result, the effects of acids were constant when $2 \sim 4 \mathrm{~m} \ell$ of nitric acid or hydrofluoric acid was contained in $50 \mathrm{~m} \ell$ of the solution. It was, therefore, decided to use $12 \mathrm{~m} \ell$ of a $1: 1: 1$ mixture of nitric acid, hydrofluoric acid and water for the dissolution of $0.5 \mathrm{~g}$ of the chips of heat-resisting alloy.

\section{Effects of base elements and the other elements}

The chemical composition of beat-resisting alloys varies from alloy to alloy. The calibration curve method is more suitable than the standard addition method for the determination of $\mathrm{Ag}$ in a wide variety of heat-resisting alloys because of the simplicity. The effect of $\mathrm{Ni}$ or $\mathrm{Co}$, a base element of heat-resisting alloys, on the absorbance of $\mathrm{Ag}$ was investigated and is shown in Table 3. It is shown that the same absorbance of $\mathrm{Ag}$ was seen in the acid solution and in the solution containing $10 \mathrm{mg} / \mathrm{m} \ell$ of $\mathrm{Ni}$ or Co as a matrix element. The effects of the other elements, which are contained generally in complex $\mathrm{Ni}$ - and Co-base heat-resisting
Table 3 Effect of $\mathrm{Ni}$ or Co matrix element* on the relative absorbance of $\mathrm{Ag}$. (Ag added: $0.01 \mu \mathrm{g} / \mathrm{m} \ell$ )

\begin{tabular}{cccc}
\hline \multirow{2}{*}{ Analyte } & \multicolumn{3}{c}{ Relative absorbance } \\
\cline { 2 - 4 } & Without matrix & $\mathrm{Ni}$ & $\mathrm{Co}$ \\
\hline $\mathrm{Ag}$ & 1.00 & 0.99 & 1.00 \\
\hline \hline
\end{tabular}

* Concentration of matrix element is $10 \mathrm{mg} / \mathrm{m} \ell$.

Table 4 Effect of $\mathrm{Cr}$ on the relative absorbance of $\mathrm{Ag}$ in solutions containing $\mathrm{Ni}$ or $\mathrm{Co}$ as a main matrix element. (Ag added: $0.01 \mu \mathrm{g} / \mathrm{m} \ell$ )

\begin{tabular}{lcccc}
\hline \multirow{2}{*}{$\begin{array}{c}\text { Main } \\
\text { matrix }\end{array}$} & \multicolumn{4}{c}{ Relative absorbance } \\
\cline { 2 - 5 } & $\begin{array}{c}\text { Without } \\
\text { Cr* }\end{array}$ & $\begin{array}{c}10 \mathrm{wt}^{\circ} \% \\
\mathrm{Cr}^{*}\end{array}$ & $\begin{array}{c}20 \mathrm{wt}^{\circ} \% \\
\mathrm{Cr}^{*}\end{array}$ & $\begin{array}{c}30 \mathrm{wt}^{\circ} \% \\
\mathrm{Cr}^{*}\end{array}$ \\
\hline $\mathrm{Ni}$ & 1.00 & 1.02 & 1.03 & 0.98 \\
$\mathrm{Co}$ & 1.00 & 0.99 & 0.99 & 0.95 \\
\hline \hline
\end{tabular}

* Concentration of $\mathrm{Cr}$ is $0.1 \mathrm{X} \mathrm{mg} / \mathrm{m} \ell$ and that of $\mathrm{Ni}$ or Co is $(10-0.1 \mathrm{X}) \mathrm{mg} / \mathrm{m} \ell$, where $\mathrm{X}$ means wt $\%$ of $\mathrm{Cr}$ in solutions containing $\mathrm{Ni}$ or $\mathrm{Co}$ as a main matrix element.

alloys, on the absorbance of $\mathrm{Ag}$ were also investigated. The experimental errors of the relative absorbance were within $\pm 5 \%$. Table 4 shows that $\mathrm{Cr}$ did not affect the absorbance of $\mathrm{Ag}$ up to $30 \mathrm{wt} \%$ of the total matrix concentration in the solutions containing $\mathrm{Ni}$ or $\mathrm{Co}$ as a main matrix element. The effects of the diverse elements on the absorbance of $\mathrm{Ag}$ were investigated up to $10 \mathrm{wt} \%$ of the total matrix concentration of $10 \mathrm{mg} / \mathrm{m} \ell$. Table 5 shows that the diverse elements did not affect the absorbance of $\mathrm{Ag}$ in this concentration range in the solutions containing $\mathrm{Ni}$ or $\mathrm{Co}$ as a main matrix element except for $\mathrm{Al}$ and $\mathrm{Ti}$ in Co solutions. Aluminum and $\mathrm{T} j$ decreased the absorbance of $\mathrm{Ag}$ in the solutions containing $\mathrm{Co}$ as a main matrix element. However, except for such cases, the acid solutions of $\mathrm{Ag}$ can be used as the calibration solutions for the determination of sub-ppm levels of Ag in Ni- and Co-base heatresisting alloys.

\section{Determination of $\mathbf{A g}$ in the samples}

Maximum sampling concentration of heatresisting alloy was investigated by using MARM 246 Ni-base alloy. It was possible to dissolve the chips up to $1 \mathrm{~g}$ in $50 \mathrm{~m} \ell$ of the solution 
Table 5 Effects of diverse elements on the relative absorbance of $\mathrm{Ag}$ in solutions containing $\mathrm{Ni}$ or Co as a main matrix element. (Ag added: $0.01 \mu \mathrm{g} / \mathrm{m} \ell$ )

(1) $\mathrm{Ni}$

\begin{tabular}{rccccccccccc}
\hline $\begin{array}{c}\text { Wt } \% \text { of } \\
\text { diverse } \\
\text { element }\end{array}$ & $\begin{array}{c}\text { Without } \\
\text { diverse } \\
\text { element* }\end{array}$ & $\mathrm{Al}$ & $\mathrm{Ti}$ & $\mathrm{Mn}$ & $\mathrm{Fe}$ & $\mathrm{Zr}$ & $\mathrm{Nb}$ & $\mathrm{Mo}$ & $\mathrm{Ta}$ & $\mathrm{W}$ \\
\hline $5^{*}$ & 1.00 & 1.02 & 1.01 & 1.00 & 1.00 & 1.01 & 0.99 & 1.01 & 1.01 & 1.02 \\
$10^{*}$ & 1.00 & 1.01 & 0.99 & 1.01 & 1.00 & 1.02 & 0.98 & 1.04 & 1.02 & 1.01 \\
\hline \hline
\end{tabular}

(2) $\mathrm{Co}$

\begin{tabular}{ccccccccccc}
\hline \hline $\begin{array}{c}\text { Wt \% of } \\
\text { diverse } \\
\text { element }\end{array}$ & $\begin{array}{c}\text { Without } \\
\text { diverse } \\
\text { element* }\end{array}$ & $\mathrm{Al}$ & $\mathrm{Ti}$ & $\mathrm{Mn}$ & $\mathrm{Fe}$ & $\mathrm{Zr}$ & $\mathrm{Nb}$ & $\mathrm{Mo}$ & $\mathrm{Ta}$ & $\mathrm{W}$ \\
\hline $5^{*}$ & 1.00 & 0.99 & 0.92 & 1.02 & 0.97 & 1.01 & 1.04 & 1.03 & 1.04 & 1.01 \\
$10^{*}$ & 1.00 & 0.94 & 0.85 & 0.99 & 0.97 & 0.96 & 0.99 & 0.99 & 1.03 & 0.98 \\
\hline \hline
\end{tabular}

* Concentration of diverse element is $0.1 \mathrm{X} \mathrm{mg} / \mathrm{m} \ell$ and that of $\mathrm{Ni}$ or $\mathrm{Co}$ is $(10-0.1 \mathrm{X}) \mathrm{mg} / \mathrm{m} \ell$, where X means $\mathrm{wt} \%$ of diverse element in solutions containing $\mathrm{Ni}$ or $\mathrm{Co}$ as a main matrix element.

Table 6 Comparison of the results obtained by the calibration curve method and the standard addition method.

\begin{tabular}{|c|c|c|c|}
\hline \multirow[b]{2}{*}{ Alloy } & \multicolumn{3}{|c|}{ Concentration of $\mathrm{Ag}(\mathrm{ppm})$} \\
\hline & $\begin{array}{l}\text { Calibration } \\
\text { curve method }\end{array}$ & $\begin{array}{l}\text { Standard addition } \\
\text { method }\end{array}$ & $\begin{array}{l}\text { Solvent extraction- } \\
\text { flame AAS }\end{array}$ \\
\hline NBS 349 & 0.14 & 0.15 & 0.2 \\
\hline Inconel $738 \mathrm{LC}$ & 0.17 & 0.17 & \\
\hline MAR-M 246 & 0.04 & 0.04 & \\
\hline Udimet $\mathrm{C} 0263$ & 0.09 & 0.09 & \\
\hline NBS 168 & 0.89 & 0.91 & 0.9 \\
\hline WI-52 & 0.53 & 0.53 & \\
\hline Modified S-816 & 0.23 & 0.22 & \\
\hline
\end{tabular}

(20 $\mathrm{mg} / \mathrm{m} \ell$ ). However, at higher concentrations, the precipitate was observed and the absorbance of $\mathrm{Ag}$ largely increased. The detection limit was $0.005 \mathrm{ppm}$ on the basis of $1 \mathrm{~g}$ sampling, which was defined as the concentration of $\mathrm{Ag}$ in the sample that produced the absorbance twice the fluctuation of background.

Sub-ppm levels of $\mathrm{Ag}$ in $\mathrm{Ni}$ - and Co-base heat-resisting alloys were determined by the calibration curve method. Table 6 compares the results by this method with the results by the standard addition method, together with those by Burke ${ }^{(1)}$. The results indicated that $\mathrm{Ag}$ could be determined with good precision by the calibration curve method. The method described above is of course applicable to determine $\mathrm{Ag}$ in $\mathrm{Ni}$ or Co metal and in high-Ni or high-Co alloys. For example, $\mathrm{Ag}$ in highpurity $\mathrm{Ni}$ and Co sponge (Johnson Matthey Chemicals Ltd., JMC 891 and JMC 870, respectively) was determined to be 0.05 and 0.18 ppm, respectively, by this method.

\section{REFERENCES}

(1) K. E. Burke: Talanta, 21 (1974), 417.

(2) M. Kirk, E. G. Perry and J. M. Arritt: Anal. Chim. Acta, 80 (1975), 163.

(3) T. R. Dulski and R. R. Bixler: Anal. Chim. Acta, 91 (1977), 199.

(4) O. Kujirai, T. Kobayashi and E. Sudo: Trans. JIM, 18 (1977), 775.

(5) R. Woodriff, B. R. Culver, D. Shrader and A. B. Super: Anal. Chem., 45 (1973), 230. 